The engineered phytoremediation of ionic and methymercury pollution

Subject line: DE-FG07-96-ER20257.EMSP 70054 Final Report

Principal Investigator: Richard B. Meagher, Department of Genetics, Life Sciences Building, Green Street, University of Georgia, Athens, GA 30602, phone: 706-542-1444, fax: 706-5421387, email: Meagher@arches.uga.edu

Graduate students working on EMSP project

\begin{tabular}{|l|l|l|l|}
\hline Student & Position & $\begin{array}{l}\text { \% Time } \\
\text { Project }\end{array}$ & Current Status \\
\hline Sarah Marshburn & Genetics Graduate Student with RBM & $100 \%$ & $\begin{array}{l}\text { Beginning Ph.D. 2002- Joining } \\
\text { laboratory June, 2003. }\end{array}$ \\
\hline Andrew Heaton & Ecology Graduate Student with RBM & $100 \%$ & $\begin{array}{l}\text { Ph.D. candidate, Finishing Dec., } \\
2002\end{array}$ \\
\hline Anne Marie Zimeri & Genetics Graduate Student with RBM & $100 \%$ & Ph.D. candidate, Finish 2003-2004 \\
\hline Raoufa Rahman & $\begin{array}{l}\text { Graduate Student - Alexandria Univ., } \\
\text { Alexandria, Egypt -RBM is Co-Advisor }\end{array}$ & $100 \%$ & $\begin{array}{l}\text { Ph.D. candidate - Finishing June, } \\
2003\end{array}$ \\
\hline
\end{tabular}

\title{
FINAL PROGRESS REPORT
}

\section{RESEARCH OBJECTIVE}

Our long-term objective is to enable highly productive plant species to extract, resist, detoxify, and/or sequester toxic organic and heavy metal pollutants (Meagher, 2000) applying scientific strategies and technologies from a rapidly developing field called phytoremediation. The phytoremediation of toxic elemental and organic pollutants requires the use relatively different approaches (Meagher, 2000). Our current specific objectives are to use transgenic plants to control the chemical species, electrochemical state, and aboveground binding of mercury to a) prevent methylmercury from entering the food-chain, b) remove mercury from polluted sites, and c) hyperaccumulate mercury in aboveground tissues for later harvest. Various parts of this strategy are being critically tested by examining different genes in model plants and field species and comparing the results to control plants as recently reviewed (Meagher et al., 2000; Rugh et al., 2000). A positive spin off of this work has been a strategy for the phytoremediation of arsenic (Dhankher et al., 2002). 


\section{RESEARCH PROJECT AND IMPLICATIONS}

During the last grant period we focused our efforts on examining transgenic plant species that would be more useful along and in aquatic environments where methylmercury is a produced (e.g., rice and cottonwood) and expanding the genetic capabilities of model plants to hyperaccumulation. We completed many physiological experiments with transgenic tobacco, cottonwood and rice. MerA expressing tobacco (Heaton et al., in prep.), cottonwood (Che et al., submitted) and rice (Heaton et al., submitted) plants are extremely resistant to mercury even in sediments where it is quite toxic and kills wild-type control cottonwood plants.

Methylmercury ( $\mathrm{MeHg}$ ) produced by native bacteria at mercury-contaminated wetland sites is a far more serious problem than $\mathrm{Hg}$ (II). $\mathrm{MeHg}$ is inherently more toxic than $\mathrm{Hg}(\mathrm{II})$, is efficiently biomagnified by several orders of magnitude in the food chain, and poses the most immediate threat to animal populations. $\mathrm{MeHg}$ is responsible for the vast majority of cases of mercury poisoning from mercury contaminated fish. $\mathrm{MeHg}$ has been a major focus of our research for the last two years. Model plants, Arabidopsis and tobacco, have been transformed with a modified bacterial organomercurial lyase gene $(m e r B)$ to degrade methylmercury and other forms of organic mercury (PMA) to the less toxic $\mathrm{Hg}(\amalg)$ (Bizily et al., 1999). Arabidopsis plants expressing both merA and $m e r B$ are resistant to even higher levels of $\mathrm{MeHg}$ and are capable of efficiently converting $\mathrm{MeHg}$ to $\mathrm{Hg}(0)$ at levels 1000 times faster than control plants (Bizily et al., 2000) as shown in the figure below. However, this research demonstrated conclusively that MerB activity is rate limiting in the coupled MerA/MerB catalyzed reaction. During the last year (2000/2001) we focused on improving the efficiency of MerB activity by targeting the enzyme to subcellular environments (Bizily et al., 2002). In a very significant finding, MerB enzyme targeted to the endoplasmic reticulum (ER) or through the ER to the cell wall processes methylmercury 10 to 20 times more efficiently than cytoplasmic MerB.

Subcellular targeting of enzymes is an exciting new breakthrough for phytoremediation of toxic heavy metals or organics. Our work suggests that native macrophytes (e.g., trees, shrubs, grasses) can be engineered to thrive on and detoxify the most abundant forms of ionic and organic mercury at polluted sites (Meagher, 2000; Meagher et al., 2000).

During this last grant year we focused research in three new areas, each with the aim of developing plants that hyperaccumulate mercury and other metals. First, a postdoctoral fellow, 
Yujing $\mathrm{Li}$, isolated genes encoding the three enzymes in the phytochelatin synthesis pathway $\gamma$ glutamylcysteine synthetase ( $E$. coli)(Li et al., submitted), glutathione synthetase ( $E$. coli) (Li et al., in prep.) and phytochelatin synthetase (fission yeast, Arabidopsis, genes in collaboration with Dr. J. Schroeder) (Li et al., in preparation). They were cloned for constitutive plant expression (all tissues and organs) and for focused expression aboveground in leaves and stems. These constructs have been tested in transgenic Arabidopsis and show that plants expressing any one of these three enzymes are more resistant to mercury and arsenic than control plants. In addition, we isolated three specific monoclonal antibodies to monitor the plant expression levels of three of these proteins using a novel rapid immunological protocol developed in our laboratory ( $\mathrm{Li}$ et al., 2001). Second, a graduate student isolated several of the diverse Arabidopsis metallothionein genes and demonstrated their differential binding specificities for $\mathrm{Hg}(\mathrm{II})$ and other metal ions (Zimeri et al., in prep).

Third, we examined three new promoter systems for expressing phytoremediating enzymes like MerA and MerB. We developed the ACT2pt ( $\mathrm{pt}=$ promoter terminator) system, based on Arabidopsis actin gene ACT2 (Balish, in prep.). ACT2pt/merA expresses MerA protein at 5 times higher levels than the widely accepted $35 \mathrm{Sp} / \mathrm{NOSt}$ constitutive expression system. Dr. Balish has shown that $A C T 2 p t / m e r A$ appears to be more consistent in being expressed in nearly all transgenic Arabidopsis and tobacco lines tested instead of only $60-70 \%$ of the $35 \mathrm{Sp} / \mathrm{merA} / \mathrm{NOSt}$ lines. Similarly, we developed SRS1pt based on our previous work a decade ago on the light induced SRS1 soybean rubisco small subunit gene (Dhankher et al., 2002; Li et al., submitted). This new cassette expresses very high levels of a GUS reporter in leaves, but not roots. It will be used to express genes that assist with the hyperaccumulation of metals in above-ground tissue. A third plant promoter system was obtained from a European laboratory for root-specific expression of MerA and MerB, to be used as part of our mercury hyperaccumulation efforts (Heaton, in prep.). This tobacco promoter is active in roots, but further research is needed to see if it is expressed strongly and specifically enough for efficient expression of merA and detoxification of $\mathrm{Hg}(\mathrm{II})$ in roots.

\section{PLANNED ACTIVITIES ON SUBMITTED RENEWAL}

In order to advance this mercury phytoremediation strategy, our research has focused on the following Specific Aims and we have made the initial progress indicated on all six: (1) to 
increase the transport of mercury to aboveground tissue through the root expression of MerA; (2) to identify small mercury binding peptides that enhance hyperaccumulation aboveground (initial results are positive with EC and MerP peptides); (3) to test the ability of multiple genes acting together to enhance resistance and hyperaccumulation (several new gene combinations have been quite successful); (4) to construct a simple molecular system for creating male/female sterility, allowing engineered grass, shrub, and tree species to be released indefinitely at contaminated sites (initial data are positive on model plants engineered with remediable nutrientbased sterility); (5) to test the ability of transgenic cottonwood and rice plants to detoxify ionic mercury and prevent methymercury release from contaminated sediment (a significant reduction of mercury from sediment was demonstrated); and (6) to conduct field testing with transgenic plants for the remediation of mercury (the initial results of which demonstrate significant reductions in total mercury in a three month period). The results of these experiments will enable the phytoremediation of methyl- and ionic mercury by a wide spectrum of deep-rooted, fast-growing plants adapted to diverse environments.

\section{INFORMATION ACCESS (PUBLICATIONS AND WEB SITE)}

Bizily, S., Kim, R., Kandasamy, M., and Meagher, R.B. (2002). Subcellular targeting of methylmercury lyase enhances its specific activity for organic mercury detoxification in plants. Plant Physiol. in press.

Bizily, S., Rugh, C.L., and Meagher, R.B. (2000). Phytodetoxification of hazardous organomercurials by genetically engineered plants. Nat. Biotechnol. 18, 213-217.

Bizily, S., Rugh, C.L., Summers, A.O., and Meagher, R.B. (1999). Phytoremediation of methylmercury pollution: merB expression in Arabidopsis thaliana confers resistance to organomercurials. Proc Natl Acad Sci USA 96, 6808-6813.

Che, D.S., Meagher, R.B., Heaton, A.C.P., Lima, A., and Merkle, S.A. (submitted). Expression of mercuric ion reductase in eastern cottonwood confers mercuric ion reduction and resistance.

Dhankher, O.P., Li, Y., Rosen, B.P., Shi, J., Salt, D., Senecoff, J.F., Sashti, N.A., and Meagher, R.B. (2002). Engineering tolerance and hyperaccumulation of arsenic in plants by combining arsenate reductase and gamma-glutamylcysteine synthetase expression. Nat Biotechnol 20, 1140-5. 
Heaton, A., Rugh, C., and Meagher, R. (in prep.). Genetically engineered Nicotiana tabacum as a model for mercury phytoremediation. Plant Phys.

Heaton, A., Rugh, C., Wang, J., Kim, R., and Meagher, R. (submitted). Toward detoxifying mercury-polluted aquatic sediments using rice genetically-engineered for mercury resistance. Environmental Toxicology and Chemistry

Li, Y., Kandasamy, M.K., and Meagher, R.B. (2001). Rapid isolation of monoclonal antibodies: monitoring enzymes in the phytochelatin synthesis pathway. Plant Physiol. 127, 711-719.

Li, Y., Parkash Dhankher, O., and Meagher, R. (in prep.). Engineering metal hyperaccumulation: $\Pi$. Overexpression of glutathione synthetase in plants confers high level arsenic and mercury resistance.

Li, Y., Parkash Dhankher, O., and Meagher, R. (submitted). Engineering metal hyperaccumulation: I. Overexpression of $\gamma$-glutamylcysteine synthetase in plants confers high level arsenic and mercury tolerance.

Li, Y., Parkash Dhankher, O., Schroeder, J., and Meagher, R. (in preparation). Engineering metal hyperaccumulation: III. Leaf-specific expression of phytochelatin synthase in plants confers high level arsenic and mercury resistance.

Meagher, R.B. (2000). Phytoremediation of toxic elemental and organic pollutants. Curr. Opin. Plant Biol. 3, 153-162.

Meagher, R.B., Rugh, C.L., Kandasamy, M.K., Gragson, G., and Wang, N.J. (2000). Engineered phytoremediation of mercury pollution in soil and water using bacterial genes. In: Phytoremediation of Contaminated Soil and Water, N. Terry, and G. Banuelos, eds (Boca Raton: Lewis Publishers), pp. 203-221.

Rugh, C.L., Bizily, S.P., and Meagher, R.B. (2000). Phytoremediation of environmental mercury pollution. In: Phytoremediation of toxic metals: Using plants to clean-up the environment, B. Ensley, and I. Raskin, eds (New York: Wiley and Sons), pp. 151-169. 